\title{
The effects of dietary a-linolenic acid on growth performance, meat quality, fatty acid composition and liver relative enzyme mRNA expression of growing meat rabbits
}

\author{
H.T. Du, C.Y. Wang, X.P. Wang, M.W. Ma and F.C. Li ${ }^{1}$ \\ Shandong Agricultural University, College of Animal Science and Technology, \\ Tai'an, Shandong, 271018, P.R. China
}

KEY WORDS. rabbit, a-linolenic acid, growth performance, meat quality, fatty acids, mRNA expression

Received: 07 February 2013

Revised: 10 May 2013

Accepted: 13 June 2013

${ }^{1}$ Corresponding author: e-mail: chlf@sdau.edu.cn

\begin{abstract}
The effects of five levels of added a-linolenic acid (ALA) $(0,1,2$, 3 , and $4 \mathrm{~g} \cdot \mathrm{kg}^{-1}$ diet, as-fed basis) in diets on growth performance, meat quality, fatty acid composition of muscle and liver, and expression of acetyl-CoA carboxylase (ACC) and carnitine palmitoyl transferase 1 (CPT1) mRNA in the liver of growing meat rabbits were studied. A quadratic effect of ALA addition on average daily intake was found $(P<0.0001)$. ALA addition had a significant influence on muscle colour of longissimus lumborum (LL), including $L^{*}, a^{*}$, and $b^{*}(P<0.0001, P=0.0007$, and $P=0.0120$, respectively). The monounsaturated fatty acid (MUFA) content of LL decreased as dietary ALA increased $(P=0.0001)$ and the polyunsaturated fatty acid (PUFA) and C18:3 (n-3) contents in the LL and liver increased with dietary ALA increase $(P=0.0006$, $P<0.0001, P<0.0001$, and $P<0.0001$, respectively). The expression of ACC mRNA in the liver decreased $(P<0.0001)$, that of CPT 1 , increased $(P<0.0001)$ as dietary ALA increased.
\end{abstract}

\section{Introduction}

Numerous studies have illustrated that polyunsaturated fatty acids (PUFAs) have beneficial effects on normal health and chronic diseases, such as regulation of lipid levels, cardiovascular and immune functions. Another important action of n-3 fatty acids is that they can play a key role in the prevention and management of several diseases, including coronary heart disease, dyslipidaemia, type 2 diabetes, insulin resistance, hypertension. In addition, they are essential for normal growth and development (Gillingham et al., 2005; Lombardo and Chicco, 2006; Lunn and Buttriss, 2008).

Standard rabbit meat is already a quite good source of unsaturated fatty acids (UFA) and linoleic acid (LA) (Dalle Zotte and Szendro, 2011) because these acids represent about $60 \%$ and $22 \%$ of total fatty acids, respectively. Rabbit meat can be effectively used to produce functional meat and meat products, since manipulation of the rabbit diet is very effective in increasing the levels of n-3 PUFA (Kouba et al., 2008; Tres et al., 2008). Consequently, from a nutritional point of view, enrichment of rabbit meat with PUFA n-3 is more interesting (Dal Bosco et al., 2004; Bianchi et al., 2006, 2009; Kouba et al., 2008; Peiretti and Meineri, 2008). It has been confirmed that many enzymes synthesized in the liver and involved in fatty acid synthesis are affected by PUFA, such as acetyl-CoA carboxylase (ACC), fatty acid synthetase (FAS), carnitine palmitoyl transferase (CPT), and so on. Notwithstanding, however, reports about the influence of dietary PUFA on ACC, FAS, and CPT are scarce. 
The objectives of the present study were to investigate and discuss the effects of ALA on growth performance, meat quality, muscle and liver fatty acid composition in growing meat rabbits. In addition, the effects of dietary ALA concentration on ACC and carnitine palmitoyl transferase 1 (CPT 1) mRNA expression in the liver were also determined.

\section{Material and methods}

\section{Animals and diets}

One hundred and fifty crossbred New Zealand White $\times$ local White ( 9 weeks old) rabbits were allocated to five groups of 30 rabbits each ( 15 males and 15 females). The rabbits were individually housed in metabolism cages $(60 \times 40 \times 40 \mathrm{~cm})$ with free access to water. During the trial, the rabbits were housed in a closed and ventilated building in which the maximum temperature was $5^{\circ} \mathrm{C}$ and the minimum temperature, $-5^{\circ} \mathrm{C}$ (winter) and the relative humidity ranged from $50 \%$ to $60 \%$. A cycle of $12 \mathrm{~h}$ of light and $12 \mathrm{~h}$ of dark was used throughout this trial.

Diets appropriate for growth stage were formulated according to NRC (1977) and de Blas and Mateos (1998) and were pelleted by the use of pressure (Table 1). The diameter of the pellets was $4 \mathrm{~mm}$. The amount $\alpha$-linolenic acid (ALA) added to the five experimental diets was $0,1,2,3$ and $4 \mathrm{~g} \cdot \mathrm{kg}^{-1}$ diet (as-fed basis) and the total ALA concentrations ranged from $0.7-4.1 \mathrm{~g} \cdot \mathrm{kg}^{-1}$ in the diet, respectively.

\section{Experimental procedures}

The experiment lasted for 4 weeks that included a 1-week adaptation period and a 3-week experimental period. Feeds were provided ad libitum and the feeder was refilled at 8.30 and 17.30 daily. The residual feed was collected each day from the cages.

The weight of each rabbit was measured at the beginning and the end of the trial and the average daily gain (ADG) calculated. The average daily feed intake (ADI) was calculated according to total feed intake divided by total experimental days, and the feed-to-gain $(\mathrm{F} / \mathrm{G})$ ratio was calculated. The $\mathrm{ADG}, \mathrm{ADI}$, and $\mathrm{F} / \mathrm{G}$ calculations did not include the 7-day adjustment period.

At the end of the trial, 40 rabbits ( 8 rabbits per group, 4 males and 4 females, chosen so that the average body weight of the 8 rabbits equaled the average body weight of the entire treatment group) were electrically stunned ( $70 \mathrm{~V}$, pulsed direct current, $50 \mathrm{~Hz}$ for $5 \mathrm{sec}$ ) and killed by cervical dislocation $1 \mathrm{~h}$ before dark. The hot carcass weight (weight of the carcass 15-30 min after slaughter) and chilled carcass weight (weight of the above carcass after chilling for $24 \mathrm{~h}$ at $0-4^{\circ} \mathrm{C}$ starting about one hour after slaughter) were determined and the dressing-out and drip-loss percentages were calculated.

At slaughtering, the liver was immediately removed from each carcass. Meanwhile, the whole longissimus lumborum (LL) (between the $1^{\text {st }}$ and $7^{\text {th }}$ lumber vertebra) was removed from the right side of each carcass. LL was then divided into four subsamples. One of these was used for $\mathrm{pH}$ measure-

Table 1. Ingredients and chemical composition of the experimental diets

\begin{tabular}{|c|c|c|c|c|c|}
\hline \multirow{2}{*}{ Indices } & \multicolumn{5}{|c|}{ a-Linolenic acid concentrations in the diet, $\mathrm{g} \cdot \mathrm{kg}^{-1}$} \\
\hline & 0.7 & 1.4 & 2.1 & 3.8 & 4.1 \\
\hline \multicolumn{6}{|l|}{ Ingredient, $\mathrm{g} \cdot \mathrm{kg}^{-1}$ diet } \\
\hline maize grain & 211.9 & 207.9 & 203.9 & 200.9 & 196.9 \\
\hline soya bean meal $(\mathrm{CP}, 442.0)$ & 161 & 161 & 161 & 161 & 161 \\
\hline wheat bran & 180 & 180 & 180 & 180 & 180 \\
\hline peanut vine, chopped & 397.1 & 399.8 & 402.6 & 404.3 & 407.1 \\
\hline a-ethyl linolenate ${ }^{1}$ & 0 & 1.3 & 2.5 & 3.8 & 5.0 \\
\hline Premix ${ }^{2}$ & 50 & 50 & 50 & 50 & 50 \\
\hline \multicolumn{6}{|l|}{ Chemical composition (calculated) } \\
\hline digestible energy ${ }^{3}, \mathrm{MJ} \cdot \mathrm{kg}^{-1}$ & 10.26 & 10.26 & 10.27 & 10.28 & 10.29 \\
\hline crude protein, $\mathrm{N} \times 6.25, \%$ & 15.91 & 15.91 & 15.91 & 15.91 & 15.91 \\
\hline crude fibre, $\%$ & 14.01 & 14.08 & 14.16 & 14.20 & 14.27 \\
\hline methionine + cysteine, $\%$ & 0.45 & 0.45 & 0.45 & 0.45 & 0.45 \\
\hline lysine, $\%$ & 0.57 & 0.57 & 0.57 & 0.57 & 0.57 \\
\hline $\mathrm{Ca}, \%$ & 0.6 & 0.6 & 0.6 & 0.6 & 0.6 \\
\hline total phosphorus, $\%$ & 0.54 & 0.54 & 0.54 & 0.54 & 0.54 \\
\hline a-linolenic acid, $\mathrm{g} \cdot \mathrm{kg}^{-1}$ & 0.7 & 1.4 & 2.1 & 3.8 & 4.1 \\
\hline
\end{tabular}

${ }^{1} a$-ethyl linolenate came from Beijing Haoersi Technology Co., Ltd. and the content of a-linolenic acid was $80 \% ;{ }^{2}$ the premix provides following for a kg of diet: IU: vit. A 8000, vit. D 1000 ; mg: vit. E 50; vit. K 2; Cu 40, Fe 100, Zn 50, Mn 30, I 0.5, Se 0.5, zinc bacitracin 300; g: met 2, $\mathrm{CaHPO}_{4} 15$, lys 2 , salt 5 ; the other rest was maize; ${ }^{3}$ calculated values according to the tables of feed composition and nutritive values in China (The $20^{\text {th }}$ revised Edition, 2009) 
ment. Muscle colour $\left(\mathrm{L}^{*}, \mathrm{a}^{*}\right.$ and $\left.\mathrm{b}^{*}\right)$, shear force, and drip-loss percentage were determined at the end of the chilling period ( $24 \mathrm{~h}$, day 1$)$ on subsamples two and three, respectively. The fourth section of the LL, as well as the liver were frozen immediately in liquid nitrogen and subsequently stored at $-70^{\circ} \mathrm{C}$ until analysed for fatty acid composition, ACC and CPT 1 mRNA expression.

\section{Physical and chemical analysis}

The dressing-out percentage and drip-loss percentage of the LL were calculated according to the following formulae introduced by Blasco and Ouhayoun (1993): dressing-out percentage $(\%)=$ chilled carcass weight/liveweight $\times 100 \%$. Driploss percentage $(\%)=($ hot carcass weight - chilled carcass weight $) /$ hot carcass weight $(\%)$. The $\mathrm{pH}$ value was determined from each rabbit 45 min postmortem and on day 1 with a $\mathrm{pH}$ meter equipped with a $\mathrm{pH}$ probe penetrating $3 \mathrm{~mm}$ into the LL.

Shear force $(\mathrm{kg} \cdot \mathrm{f})$ of the LL was evaluated on cores $(1.25 \times 2 \mathrm{~cm})$ obtained from the mid-portions of the cooked samples (cooked in a water bath at $80^{\circ} \mathrm{C}, 10 \mathrm{~min}$ ) of the LL by cutting them perpendicularly to fibre direction, using the Warner-Blatzler meat shear apparatus (C-LM, USA). Three samples of per LL were used for shear force measurement and the values were averaged. The colour includes $\mathrm{L}^{*}$ (lightness or brightness), $\mathrm{a}^{*}$ and $\mathrm{b}^{*}$ (redness and yellowness) parameters and was measured at a depth of $3 \mathrm{~mm}$ on the muscle cut surface by a CR100 Chroma Meter (Minolta, Tokyo, Japan).

The total lipids were extracted from the LL and liver samples by the method of Folch et al. (1957). Eight grams of the sample were homogenized with a $2: 1(\mathrm{v} / \mathrm{v})$ mixture of chloroform-methanol. After standing for $2 \mathrm{~h}$ the lower layer was withdrawn and concentrated in a rotary evaporator in a water bath at $60^{\circ} \mathrm{C}$, under $\mathrm{N}_{2}$ flow. Transmethylation was carried out using a mixture of methanol, benzene, and sulphuric acid (75:25:4). Gas chromatography was performed on a Shimadzu GC-2014 (Shimadzu Corp. Tokyo, Japan) apparatus equipped with a DB-23 type capillary column $(0.25 \mathrm{~mm} \times 30 \mathrm{~m}$ $\times 0.25 \mu \mathrm{m})$ and flame ionization detector. Direct injection onto the column was performed with $0.25 \mu 1$ samples. Characteristic operating conditions were: the carrier gas was $\mathrm{N}_{2}$ with a flow rate of $24 \mathrm{ml} \cdot \mathrm{min}^{-1}, \mathrm{H}_{2}$ and air flows to the detector were $60 \mathrm{ml} \cdot \mathrm{min}^{-1}$. Injector and detector temperatures were $250^{\circ} \mathrm{C}$. The oven temperature was $210^{\circ} \mathrm{C}$. Fatty acids were identified by comparison of the retention times with known standard mixtures of fatty acid methyl esters (NU-VHEK, USA) and quantified by a Shimadzu C-RGA integrator (Shimadzu Corp. Tokyo, Japan). Results were expressed as percentage $(\mathrm{w} / \mathrm{w})$ of the total fatty acid methyl esters. The analysis was designed to detect the following fatty acids: C14:0, C16:0, C17:0, C18:0, C16:1 (n-7), C18:1 (n-9), C18:2 (n-6), C18:3 (n-6), C18:3 (n-3), C20:2 (n-6), C20:3 (n-6), C20:4 (n-6), C20:5 (n-3), C22:4 (n-6), C22:5 (n-3), C22:6 (n-3).

Total RNA was isolated from liver samples using the Trizol reagent (Invitrogen, Carlsbad, CA, USA) following the manufacturer's instructions. The RNA concentration was determined by measuring absorbance at $260 \mathrm{~nm}$. Subsequently, a $2 \mu \mathrm{g}$ sample of RNA was treated with DNase prior to reverse transcription to cDNA using a PrimeScript ${ }^{\circledR}$ RT Reagent Kit (Takara, Dalian, China). The cDNA samples were stored at $-20^{\circ} \mathrm{C}$.

To measure expression of ACC and CPT1 mRNA in the liver, real-time PCR was performed using a 7500 Real Time PCR System (Applied Biosystems, Carlsbad, CA, USA) and SYBR Premix Ex Taq Kit (Takara, Dalian, China). The volume of each PCR reaction was $50 \mu \mathrm{l}$ which included $4 \mu \mathrm{l}$ cDNA, $25 \mu \mathrm{l}$ SYBR Premix Ex Taq, $1 \mu$ l PCR forward primer, $1 \mu$ PCR reverse primer, $1 \mu \mathrm{l}$ ROX Reference Dye and $18 \mu 1$ $\mathrm{ddH}_{2} \mathrm{O}$. The forward and reverse primers for ACC (5'-TGGCTGTATCCATTATGTCAAGCG-3' and 5'-TGAAGAAAGGGTCAGGAAGGCAGTA-3', respectively), were designed according to the published sequence (Genebank accession No. XM002719077). The respective primers for CPT 1 (5'-AGGTGCTCCTCTCCTACCACGG-3' and 5'-GTTGCTGTTCACCATCAGTGGC-3') were designed according to the CPT-1 sequence (Genebank accession No. XM-002724092). Glyceraldehyde-3-phosphate dehydrogenase (GAPDH) was used as the internal control gene. The forward primer (5'-TGCCACCCACTCCTCTACCTTCG-3') and reverse primer

(5'-CCGGTGGTTTGAGGGCTCTTACT-3') were designed to amplify the GAPDH gene according to its published sequence (Genebank accession No. RABGLY3PHO). All data were normalized to the internal control GAPDH and the relative expression levels were calculated using the $2-\Delta \Delta \mathrm{Ct}$ method.

\section{Statistical analysis}

The linear and quadratic effects of ALA concentration on all parameters were analysed using regression procedures; treatment mean values were compared using Duncan's multiple range test (SAS, 1985). 


\section{Results}

\section{Growth performance}

The effect of diet on growth performance is shown in Table 2. A quadratic effect of the concentration of added ALA on ADI was found $(P<0.0001)$. No significant differences in ADG or $\mathrm{F} / \mathrm{G}$ were found among groups $(p>0.05)$.

\section{Dressing-out percentage and meat quality}

As shown in Table 2, ALA concentrations had no significant influence on dressing-out percentage, $\mathrm{pH}$ value at 45 min post-mortem and day 1 , shear force, and drip-loss percentage of experimental rabbits $(p>0.05)$. ALA concentrations had a significant influence on muscle colour of LL, including $L^{*}, a^{*}$ and $b^{*} . L^{*}$ was the highest when the ALA concentration was $3.8 \mathrm{~g} \cdot \mathrm{kg}^{-1}$ diet $(P<0.0001)$. The effects of ALA on $\mathrm{a}^{*}$ and $\mathrm{b}^{*}$ were linear $(P=0.0007,0.0120)$.

\section{Fatty acid composition in the muscle and liver}

The fatty acid composition in the longissimus lumborum (LL) is shown in Table 3. The C14:0, $\mathrm{C} 17: 0$, and $\mathrm{C} 18: 0$ contents in the LL did not differ significantly among treatments $(p>0.05)$. The C16:0, SFA, C16:1, C18:1, and MUFA contents in the LL were significantly affected by dietary ALA $(p<0.05 ; P<0.01)$ and the MUFA content of the LL decreased with dietary ALA increase $(P=0.0001)$. The dietary ALA levels significantly affected the C18:3 (n-3), C22:5 (n-3) and PUFA contents in the LL $(p<0.05 ; P<0.01)$, and the PUFA and C18:3 (n-3) contents in the LL increased with dietary ALA increase $(P<0.0001)$. The differences in $n-3$ con- tents and the n-6-to-n-3 ratio in the LL of different treatments were significant $(P<0.01)$, the differences in n- 6 contents in the LL of different treatments were not significant $(p>0.05)$.

The fatty acid composition in the liver is shown in Table 4. Although the dietary ALA significantly affected C14:0 and C16:0 contents in the liver $(P<0.01)$, the SFA content in the liver did not significantly differ among treatments $(p>0.05)$. The C16:1, C18:1 and MUFA contents in the liver were significantly affected by dietary ALA $(P<0.01)$. A linear effect of ALA on the MUFA content in the liver was found $(P<0.0001)$; the MUFA content in the liver of the $4.1 \mathrm{~g} \cdot \mathrm{kg}^{-1}$ diet group was the lowest. The differences among the C18:2 (n-6), C18:3 (n-3), C20:2 (n-6), C20:5 (n-3), C22:4 (n-6), $\mathrm{C} 22: 5(\mathrm{n}-3), \mathrm{C} 22: 6(\mathrm{n}-3)$ and PUFA contents in the liver were significant $(p<0.05 ; P<0.01)$; the PUFA and $\mathrm{C} 18: 3(\mathrm{n}-3)$ contents in the liver rose as dietary ALA increased $(P<0.0001)$. The differences in $\mathrm{n}-3$ and $n-6$ fatty acid contents and the n-6-to-n-3 ratios in the liver of different treatments were significant $(P<0.01 ; p<0.05$, respectively $)$.

\section{Acetyl-CoA carboxylase and carnitine palmitoyl transferase 1 mRNA expression in the liver}

Table 5 displays the effects of different amounts of dietary ALA on acetyl-CoA carboxylase (ACC) and carnitine palmitoyl transferase 1 (CPT1) mRNA expression in the liver. The ACC mRNA expression in the liver decreased, and CPT1 mRNA expression in the liver increased as dietary ALA increased $(P<0.0001)$.

Table 2. The effect of dietary a-linolenic acid on performance $(n=30)$, dressing out percentage and meat quality $(n=8)$ of the experimental rabbits

\begin{tabular}{|c|c|c|c|c|c|c|c|c|}
\hline & \multicolumn{5}{|c|}{ a-Linolenic acid concentration in the diet, $\mathrm{g} \cdot \mathrm{kg}^{-1}$} & \multirow{2}{*}{ RMSE } & \multicolumn{2}{|l|}{$P$-value } \\
\hline & 0.7 & 1.4 & 2.1 & 3.8 & 4.1 & & linear & quadratic \\
\hline Average daily intake, $\mathrm{g} \cdot \mathrm{d}^{-1}$ & $120^{\mathrm{B}}$ & $117^{\mathrm{C}}$ & $121^{\mathrm{B}}$ & $124^{\mathrm{A}}$ & $115^{\mathrm{D}}$ & 2.35 & 0.4055 & $<0.0001$ \\
\hline Average daily gain, $g \cdot d^{-1}$ & 19.7 & 18.4 & 18.5 & 18.8 & 19.4 & 2.87 & 0.9253 & 0.2470 \\
\hline Feed/gain ratio & 6.66 & 6.30 & 6.63 & 6.47 & 6.28 & 0.77 & 0.4467 & 0.6881 \\
\hline Dressing-out percentage & 48.3 & 47.2 & 47.4 & 46.5 & 46.7 & 2.09 & 0.0983 & 0.2149 \\
\hline$L^{*}$ & $43.0^{c}$ & $45.5^{\mathrm{B}}$ & $45.0^{B C}$ & $47.8^{\mathrm{A}}$ & $46.2^{A B}$ & 2.15 & $<0.0001$ & 0.0001 \\
\hline$a^{*}$ & $1.14^{\mathrm{a}}$ & $0.17^{\mathrm{ab}}$ & $0.15^{\mathrm{ab}}$ & $-0.49^{b}$ & $-0.63^{b}$ & 0.83 & 0.0007 & 0.0029 \\
\hline$b^{*}$ & 7.18 & 6.79 & 5.88 & 6.39 & 5.84 & 0.88 & 0.0120 & 0.0329 \\
\hline Shear force, $\mathrm{kg} \cdot \mathrm{f}$ & 1.56 & 1.52 & 1.7 & 1.79 & 1.70 & 0.26 & 0.0748 & 0.1933 \\
\hline $\mathrm{pH}, 45 \mathrm{~min}$ & 6.64 & 6.62 & 6.59 & 6.64 & 6.50 & 0.10 & 0.0646 & 0.1335 \\
\hline $\mathrm{pH}, 24 \mathrm{~h}$ & 5.81 & 5.9 & 5.86 & 5.92 & 5.85 & 0.07 & 0.3390 & 0.1091 \\
\hline Drip-loss percentage & 4.52 & 5.36 & 4.26 & 5.09 & 5.06 & 1.06 & 0.5543 & 0.8371 \\
\hline
\end{tabular}

The values with different capital letters in the same row differ significantly $(P<0.01)$. The values with different small letters in the same row differ significantly $(p<0.05)$; RMSE - root mean square error 
Table 3.The effect of dietary a-linolenic acid on fatty acid composition in the longissimus lumborum (LL) of the experimental rabbits $(\%)(n=8)$

\begin{tabular}{|c|c|c|c|c|c|c|c|c|}
\hline & \multicolumn{5}{|c|}{ a-Linolenic acid concentration in the diet, $\mathrm{g} \cdot \mathrm{kg}^{-1}$} & \multirow{2}{*}{ RMSE } & \multicolumn{2}{|l|}{$P$-value } \\
\hline & 0.7 & 1.4 & 2.1 & 3.8 & 4.1 & & linear & quadratic \\
\hline C14:0 & 1.75 & 1.99 & 1.70 & 1.60 & 1.46 & 0.32 & 0.0530 & 0.1029 \\
\hline C16:0 & 30.0 & 30.8 & 29.7 & 29.1 & 27.5 & 1.99 & 0.0121 & 0.0175 \\
\hline C17:0 & 0.61 & 0.61 & 0.60 & 0.60 & 0.67 & 0.06 & 0.1317 & 0.1040 \\
\hline C18:0 & 7.81 & 7.54 & 7.63 & 7.95 & 8.24 & 0.78 & 0.2088 & 0.2367 \\
\hline SFAs & 40.2 & 40.8 & 39.7 & 39.3 & 37.8 & 2.00 & 0.0181 & 0.0302 \\
\hline C16:1 (n-7) & $2.28^{A B}$ & $2.68^{\mathrm{A}}$ & $2.36^{\mathrm{AB}}$ & $1.96^{\mathrm{BC}}$ & $1.57^{c}$ & 0.44 & 0.0020 & 0.0009 \\
\hline C18:1 (n-9) & 23.1 & 22.9 & 22.0 & 21.8 & 20.3 & 2.25 & 0.0221 & 0.0658 \\
\hline MUFAs & $25.2^{\mathrm{a}}$ & $25.6^{\mathrm{a}}$ & $24.1^{\mathrm{ab}}$ & $22.8^{\mathrm{bc}}$ & $21.9^{c}$ & 1.43 & 0.0001 & 0.0004 \\
\hline C18:2 (n-6) & 23.2 & 24.2 & 24.8 & 24.4 & 26.0 & 1.76 & 0.0164 & 0.0588 \\
\hline C18:3 (n-3) & $1.16^{c}$ & $1.27^{\mathrm{bc}}$ & $1.98^{\mathrm{ab}}$ & $2.32^{\mathrm{a}}$ & $2.50^{\mathrm{a}}$ & 0.60 & $<0.0001$ & 0.0003 \\
\hline $\mathrm{C} 20: 2(\mathrm{n}-6)$ & 0.41 & 0.45 & 0.40 & 0.40 & 0.41 & 0.13 & 0.7641 & 0.9563 \\
\hline $\mathrm{C} 20: 3(\mathrm{n}-6)$ & 0.45 & 0.51 & 0.49 & 0.56 & 0.62 & 0.21 & 0.1430 & 0.3342 \\
\hline $\mathrm{C} 20: 4(\mathrm{n}-6)$ & 6.76 & 5.78 & 7.72 & 7.45 & 8.41 & 1.78 & 0.0853 & 0.2092 \\
\hline$C 22: 4(n-6)$ & 1.13 & 1.13 & 1.23 & 1.46 & 1.40 & 0.31 & 0.0742 & 0.2127 \\
\hline$C 22: 5(n-3)$ & $0.45^{\mathrm{bc}}$ & $0.36^{c}$ & $0.63^{b c}$ & $0.88^{\mathrm{ab}}$ & $1.13^{a}$ & 0.29 & 0.0002 & 0.0007 \\
\hline PUFAs & $34.8^{\mathrm{bc}}$ & $33.4^{c}$ & $35.8^{\mathrm{bc}}$ & $38.4^{\mathrm{ab}}$ & $40.4^{a}$ & 2.92 & 0.0006 & 0.0012 \\
\hline$n-3$ & $1.43^{C}$ & $1.45^{\mathrm{C}}$ & $2.51^{\mathrm{B}}$ & $3.05^{A B}$ & $3.63^{A}$ & 0.59 & $<0.0001$ & $<0.0001$ \\
\hline$n-6$ & 31.5 & 31.8 & 33.3 & 33.9 & 36.0 & 3.42 & 0.0306 & 0.0915 \\
\hline$n-6 / n-3$ & $23.6^{A}$ & $16.1^{\mathrm{B}}$ & $13.9^{\mathrm{B}}$ & $10.3^{B}$ & $10.5^{\mathrm{B}}$ & 4.27 & $<0.0001$ & $<0.0001$ \\
\hline
\end{tabular}

The values with different capital letters in the same row differ significantly $(P<0.01)$. The values with different small letters in the same row differ significantly $(p<0.05)$; SFAs, saturated fatty acids; SFAs $(\%)=$ C14:0 + C16:0 + C17:0 + C18:0; MUFAs - monounsaturated fatty acids; MUFAs $(\%)=$ C16:1 + C18:1; PUFAs - polyunsaturated fatty acids; PUFAs $(\%)=$ C18:2 $(n-6)+C 18: 3(n-3)+C 20: 2(n-6)+C 20: 3(n-6)+C 20: 4$ $(n-6)+C 22: 4(n-6)+C 22: 5(n-3) ;$ RMSE - root mean square error

Table 4. The effect of dietary a-linolenic acid on fatty acid composition in the liver of the experimental rabbits $(\%)(n=8)$

\begin{tabular}{|c|c|c|c|c|c|c|c|c|}
\hline & \multicolumn{5}{|c|}{ a-linolenic acid concentration in the diet, $\mathrm{g} \cdot \mathrm{kg}^{-1}$} & \multirow[t]{2}{*}{ RMSE } & \multicolumn{2}{|l|}{$P$-value } \\
\hline & 0.7 & 1.4 & 2.1 & 3.8 & 4.1 & & linear & quadratic \\
\hline $\mathrm{C} 14: 0$ & $0.37^{\mathrm{A}}$ & $0.12^{\mathrm{BC}}$ & $0.26^{\mathrm{AB}}$ & $0.14^{\mathrm{BC}}$ & $0.04^{c}$ & 0.10 & 0.0005 & 0.0025 \\
\hline C16:0 & $19.0^{\mathrm{A}}$ & $18.3^{A B}$ & $19.4^{\mathrm{A}}$ & $18.4^{\mathrm{A}}$ & $17.1^{\mathrm{B}}$ & 0.94 & 0.0168 & 0.0081 \\
\hline C17:0 & 0.89 & 0.87 & 0.89 & 0.84 & 0.91 & 0.09 & 0.9321 & 0.7228 \\
\hline C18:0 & 23.0 & 25.2 & 23.5 & 23.3 & 25.5 & 1.10 & 0.1483 & 0.2593 \\
\hline SFAs & 44.0 & 44.5 & 44.0 & 43.4 & 43.6 & 1.02 & 0.1251 & 0.2861 \\
\hline C16:1 (n-7) & $0.67^{A}$ & $0.49^{B}$ & $0.64^{A}$ & $0.54^{\mathrm{AB}}$ & $0.35^{c}$ & 0.10 & 0.0024 & 0.0029 \\
\hline C18:1 (n-9) & $13.5^{\mathrm{A}}$ & $10.5^{\mathrm{B}}$ & $11.4^{\mathrm{B}}$ & $10.3^{\mathrm{B}}$ & $7.72^{\mathrm{C}}$ & 1.46 & $<0.0001$ & $<0.0001$ \\
\hline MUFAs & $13.3^{\mathrm{A}}$ & $10.9^{B}$ & $12.0^{A B}$ & $10.8^{\mathrm{B}}$ & $8.07^{c}$ & 1.33 & $<0.0001$ & 0.0001 \\
\hline C18:2 (n-6) & $28.5^{b}$ & $30.3^{b}$ & $29.8^{b}$ & $29.9^{b}$ & $32.5^{\mathrm{a}}$ & 1.71 & 0.0040 & 0.0126 \\
\hline C18:3 (n-6) & 0.22 & 0.28 & 0.22 & 0.21 & 0.33 & 0.06 & 0.1403 & 0.1029 \\
\hline C18:3 (n-3) & $0.48^{c}$ & $0.65^{c}$ & $1.16^{\mathrm{B}}$ & $1.28^{A B}$ & $1.49^{\mathrm{A}}$ & 0.18 & $<0.0001$ & $<0.0001$ \\
\hline C20:2 (n-6) & $0.87^{\mathrm{a}}$ & $0.80^{\mathrm{a}}$ & $0.76^{\mathrm{ab}}$ & $0.78^{\mathrm{a}}$ & $0.61^{\mathrm{b}}$ & 0.12 & 0.0031 & 0.0108 \\
\hline$C 20: 3(n-6)$ & 0.75 & 0.78 & 0.78 & 0.91 & 0.70 & 0.13 & 0.9850 & 0.2947 \\
\hline C20:4 (n-6) & 9.64 & 10.2 & 9.54 & 10.4 & 10.3 & 0.96 & 0.2738 & 0.5517 \\
\hline C20:5 (n-3) & - & $0.04^{\mathrm{B}}$ & $0.02^{\mathrm{B}}$ & $0.07^{\mathrm{B}}$ & $0.19^{A}$ & 0.06 & 0.0001 & $<0.0001$ \\
\hline $\mathrm{C} 22: 4(\mathrm{n}-6)$ & $1.02^{\mathrm{A}}$ & $0.98^{\mathrm{A}}$ & $0.95^{\mathrm{A}}$ & $1.03^{\mathrm{A}}$ & $0.80^{\mathrm{B}}$ & 0.11 & 0.0195 & 0.0218 \\
\hline $\mathrm{C} 22: 5(\mathrm{n}-3)$ & $0.37^{c}$ & $0.41^{\mathrm{BC}}$ & $0.53^{\mathrm{B}}$ & $0.75^{\mathrm{A}}$ & $0.82^{\mathrm{A}}$ & 0.09 & $<0.0001$ & $<0.0001$ \\
\hline $\mathrm{C} 22: 6(\mathrm{n}-3)$ & - & $0.15^{\mathrm{B}}$ & $0.15^{\mathrm{B}}$ & $0.38^{A}$ & $0.53^{\mathrm{A}}$ & 0.15 & $<0.0001$ & $<0.0001$ \\
\hline PUFAs & $41.6^{\mathrm{C}}$ & $44.5^{\mathrm{B}}$ & $43.9^{B C}$ & $45.8^{\mathrm{AB}}$ & $48.3^{A}$ & 2.17 & $<0.0001$ & 0.0002 \\
\hline$n-3$ & $0.63^{E}$ & $1.26^{D}$ & $1.86^{\mathrm{C}}$ & $2.47^{\mathrm{B}}$ & $3.20^{\mathrm{A}}$ & 0.44 & $<0.0001$ & $<0.0001$ \\
\hline$n-6$ & $41.0^{\mathrm{d}}$ & $43.3^{b}$ & $42.1^{c}$ & $43.3^{b}$ & $45.1^{\mathrm{a}}$ & 2.21 & 0.0099 & 0.0338 \\
\hline$n-6 / n-3$ & $55.3^{\mathrm{A}}$ & $36.3^{\mathrm{B}}$ & $23.1^{\mathrm{C}}$ & $18.2^{\mathrm{CD}}$ & $14.6^{\mathrm{D}}$ & 5.63 & $<0.0001$ & $<0.0001$ \\
\hline
\end{tabular}

The values with different capital letters in the same row differ significantly $(P<0.01)$; the values with different small letters in the same row differ significantly $(p<0.05)$; SFAs - saturated fatty acids; SFAs $(\%)=C 14: 0+C 16: 0+C 17: 0+C 18: 0 ;$ MUFAs - monounsaturated fatty acids; MUFAs (\%) = C16:1 + C18:1; PUFAs - polyunsaturated fatty acids; PUFAs $(\%)=C 18: 2(n-6)+C 18: 3(n-6)+C 18: 3(n-3)+C 20: 2(n-6)+C 20: 3$ $(n-6)+C 20: 4(n-6)+C 20: 5(n-3)+C 22: 4(n-6)+C 22: 5(n-3)+C 22: 6(n-3) ;$ RMSE - root mean square error; - no data 
Table 5. The effect of dietary a-linolenic acid on acetyl-CoA carboxylase (ACC) and carnitine palmitoyl transferase 1 (CPT1) mRNA expression in the liver of the experimental rabbits $(n=8)$

\begin{tabular}{|c|c|c|c|c|c|c|c|}
\hline & \multicolumn{4}{|c|}{$\begin{array}{l}\text { a-linolenic acid concentration } \\
\text { in the diet, } \mathrm{g} \cdot \mathrm{kg}^{-1}\end{array}$} & \multicolumn{3}{|c|}{ RMSE $^{\text {P-value }}$} \\
\hline & $0.7 \quad 1.4$ & 2.1 & 3.8 & 4.1 & & linear & quadratic \\
\hline$\overline{A C C}$ & $1.00^{\mathrm{A}} 0.81^{\mathrm{A}}$ & $0.55^{\mathrm{B}}$ & $0.60^{\mathrm{B}}$ & $0.39^{B}$ & 0.18 & $<0.0001$ & $<0.0001$ \\
\hline CPT1 & $1.00^{C} 1.85 B$ & ${ }^{C} 3.75^{B}$ & $6.06^{A}$ & $6.36^{A}$ & 1.70 & $<0.0001$ & $<0.0001$ \\
\hline
\end{tabular}

The values with different capital letters in the same row differ significantly $(P<0.01)$; RMSE - root mean square error

\section{Discussion}

\section{Growth performance}

In this study, the concentration of added ALA had a significant influence on the ADI and no significant influence on the $\mathrm{ADG}$ and $\mathrm{F} / \mathrm{G}$ of experimental rabbits. This is in agreement with other studies that found that productive performances of rabbits were not affected by different treatments (Dal Bosco et al., 2004; Kouba et al., 2008; Peiretti and Meineri, 2008). Our previous study also illustrated that dietary linoleic acid (LA) supplementation had not significantly affected growth performance of experimental rabbits (Li et al., 2012). The same growth performance found in all of the treatments can be explained by the similar chemical composition of our experimental diets.

In this study, the average daily gains were very low $\left(17-20 \mathrm{~g} \cdot \mathrm{d}^{-1}\right)$, while in other studies, the common daily weight gain was $30-40 \mathrm{~g} \cdot \mathrm{d}^{-1}$. These substantial differences may be due to differences in genetics and management, especially environmental temperature; we used crossbreds of New Zealand White rabbit $\times$ local White rabbit as the experimental animals and the animals were housed in a building in which the maximum temperature was $5^{\circ} \mathrm{C}$ and the minimum temperature $-5^{\circ} \mathrm{C}$.

\section{Dressing-out percentage and meat quality}

Meat quality consists of nutritional properties, sensory characteristics, health factors and technological traits and is significantly influenced by dietary factors, including fatty acids. In this study, ALA concentrations did not significantly affect dressing-out percentage, $\mathrm{pH}$ value 45 min post-mortem and on day 1 , shear force, or drip-loss percentage of experimental rabbits. Peiretti and Meineri (2008) demonstrated that diets did not significantly influence carcass yield or the proportion of various carcass parts and organs of rabbits. Our previous study also illustrated that dietary LA concentrations had no significant influence on dressing-out percentage, $\mathrm{pH}$ value, shear force, or drip-loss percent- age of the experimental rabbits. The same growth performance found in all of the treatments can be explained by the similar chemical composition of our experimental diets and the fact that small differences in fatty acids cannot affect some physical and chemical traits of meat.

In this study, the dressing-out percentage was very low (46-49\%), while commercial carcass yield in the EU is around $55 \%$ to $60 \%$. These disparities may be due to differences in genetics and slaughter weight, because we used crossbred rabbits of New Zealand White rabbit $\times$ local White rabbit as the experimental animal; the average slaughter weight of these animals was around $2000 \mathrm{~g}$.

In this study, dietary ALA concentrations significantly influenced the muscle colour of LL, including $a^{*}$ and $b^{*}$. This is in agreement with other studies showing that diet had a significant effect on the colour of the longissimus dosi muscle (Oliver et al., 1997), the meat (l. lumborum) from rabbits fed on diets containing linseed exhibited higher $a^{*}$ values (Bianchi et al., 2006, 2009). As the colour of rabbit meat is affected mainly by pre-slaughter treatment, stress and age, the differences in dietary fatty acid profiles affected the meat colour of the experimental rabbits.

\section{Fatty acid composition in the muscle and liver}

Wood et al. (2004) pointed out that interest in meat fatty acid composition stems mainly from the need to find ways to produce healthier meat, i.e. meat with a higher ratio of polyunsaturated to saturated fatty acids and a more favourable balance between $n-6$ and n-3 PUFAs. Since manipulation of the rabbit diet is very effective in increasing the levels of n-3 PUFA or CLA, there have been numerous studies dealing with the use of polyunsaturated fatty acid (PUFA)-rich diets in rabbits and their effect on the fatty acid composition of rabbit meat and fat (Kouba et al., 2008; Peiretti and Meineri, 2008; Tres et al., 2008; Bianchi et al., 2009). This was illustrated by using PUFA-rich diets in rabbits to increase the PUFA contents, especially that of n-3 PUFA contents, and decrease SFA contents.

In this study, the MUFA contents of the LL decreased, those of PUFAs and C18:3 (n-3) in the LL and liver increased with dietary ALA increase. Moreover, the highest contents of C22:5 (n-3) and C22:6 (n-3) in the LL and in the liver were found after feeding the diet supplemented with $4.1 \mathrm{~g} \cdot \mathrm{kg}^{-1}$ ALA.

This is in agreement with the above studies that found the use of a PUFA-rich diet in rabbits may 
increase the PUFA content, especially that of n-3 PUFA, and decrease the SFA content. Long-chain FAs are likely to be deposited directly in adipose tissue; ALA supplementation of the diet increased the proportion of unsaturated FAs and resulted in rabbit meat containing a higher degree of unsaturation. This is considered an important nutritional benefit for the consumer.

\section{Acetyl-CoA carboxylase and carnitine palmitoyl transferase 1 mRNA expression in the liver}

To date, it had been confirmed that many enzymes related to fatty acid synthesis were affected by PUFA, including ACC and fatty acid synthetase (FAS). ACC is a key enzyme of long-chain fatty acid synthesis. Many studies have illustrated that ACC expression may be downregulated by dietary PUFAs. Bing et al. (1996) pointed out that lipogenic gene transcription is inhibited by polyunsaturated fatty acids and illustrated that the suppression of hepatic lipogenesis is due, at least in part, to the inhibition of transcription of several genes encoding proteins involved in both lipogenesis and glycolysis, including fatty acid synthase, stearoyl-CoA desaturase, L-type pyruvate kinase, and the S14 protein. Yahagi et al. (1999) also demonstrated that ACC expression in mice may be downregulated by dietary PUFAs. At the same time, ACC mRNA expression in the liver of meat rabbits was depressed by dietary ALA.

Chatelain et al. (1996) reported that the rapid increase in the hepatic CPT 1 mRNA level that accompanies the foetal to neonatal transition in the rat is triggered by the reciprocal change in circulating insulin and long-chain fatty acid concentrations. In this study, addition of ALA to the diets of experimental rabbits also increased CPT 1 mRNA expression in the liver. This shows that ALA can significantly enhance lipid $\beta$-oxidation in animals and lower fat synthesis.

\section{Conclusions}

In this study, dietary $\alpha$-linolenic acid (ALA) concentrations significantly affected liver and muscle fatty acid composition, especially increased PUFA, C18:3 (n-3), C22:5 (n-3) and C22:6 (n-3) contents, but had little effect on growth performance or the physical traits of meat of 2- to 3-month-old growing meat rabbits.

The results also indicate that ALA affects liver acetyl-CoA carboxylase (ACC) and carnitine palmitoyl transferase 1 (CPT 1) mRNA expression. One potential mechanism of how ALA may improve the fatty acid composition of growing rabbits is through decreasing the synthesis and secretion of ACC, and increasing the synthesis and secretion of CPT 1.

Meanwhile, the effects of dietary ALA supplementation on the quantity and nutritional quality of the perirenal fat and the organoleptic quality of the meat are new indications for further scientific investigations.

\section{Acknowledgements}

This study was supported by the earmarked fund for Modern Agro-industry Technology Research System (CARS-44-B-1) and the Special Fund for Agro-scientific Research in the Public Interest (2000903006).

\section{References}

Bianchi M., Petracci M., Cavani C., 2006. Effects of dietary inclusion of dehydrated lucerne and whole linseed on rabbit meat quality. World Rabbit Sci. 14, 247-258

Bianchi M., Petracci M., Cavani C., 2009. The influence of linseed on rabbit meat quality. World Rabbit Sci. 17, 97-107

Bing R., Thelen A., Jump D.B., 1996. Peroxisome proliferator-activated receptor a inhibits hepatic S14 gene transcription. Evidence against the peroxisome proliferator-activated receptor $a$ as the mediator of polyunsaturated fatty acid regulation of S14 gene transcription. J. Biol. Chem. 271, 17167-17173

Blasco A., Ouhayoun J., 1993. Harmonization of criteria and terminology in rabbit meat research. Revised proposal. World Rabbit Sci. 4, 93-99

Chatelain F., Kohl C., Esser V., Denis Mcgarry J., Girard J., Pegorier J.P., 1996. Cyclic AMP and fatty acids increase carnitine palmitoyltransferase 1 gene transcription in cultured fetal rat hepatocytes. Eur. J. Biochem. 235, 789-798

Dal Bosco A., Castellini C., Bianchi L., Mugnai C., 2004. Effect of dietary a-linolenic acid and vitamin $\mathrm{E}$ on the fatty acid composition, storage stability and sensory traits of rabbit meat. Meat Sci. 66, 407-413

Dalle Zotte A., Szendro Z., 2011. The role of rabbit meat as functional food. Meat Sci. 88, 319-331

de Blas C., Mateos, G. G., 1998. Feed formulation. In: C. de Blas, J. Wiseman (Editors). The Nutrition of the Rabbit. CABI Publishing, New York, NY, pp. 241-253

Folch J., Lees M., Sloane Stanley G.H., 1957. A simple method for isolation and purification of total lipids from animal tissues. J. Biol. Chem. 226, 497-509

Gillingham L., Caston G., Leeson L., Hourtovenko S., Holub B.J., 2005. The effects of consuming docosahexaenoic acid (DHA)-enriched eggs on serum lipids and fatty acid compositions in statin-treated hypercholesterolemic male patients. Food Res. 38, 1117-1123

Kouba M., Benatmane F., Blochet J.E., Mourot J., 2008. Effect of a linseed diet on lipid oxidation, fatty acid composition of muscle, perirenal fat, and raw and cooked rabbit meat. Meat Sci. 80, 829-834

Li R.G., Wang X.P., Wang C.Y., Ma M.W., Li F.C., 2012. Growth performance, meat quality and fatty acid metabolism response of growing meat rabbits to dietary linoleic acid. Asian-Austr. J. Anim. Sci. 25, 1169-1177 
Lombardo Y.B., Chicco A.G., 2006. Effects of dietary polyunsaturated n-3 fatty acids on dyslipidemia and insulin resistance in rodents and humans. J. Nutr. Biochem.17, 1-13

Lunn J., Buttriss J.L., 2008. Incorporating omega-3 in the food chain why, where and how? Nutr. Bull. 33, 250-256

NRC, 1977. Nutrient Requirements of Rabbits, $2^{\text {nd }}$ Edition, National Academy Press. Washington, DC

Oliver M.A., Guerrero L., Diaz I., Gispert M., Pla M., Blasco A., 1997. The effect of fat-enriched diets on the perirenal fat quality and sensory characteristics of meat from rabbit. Meat Sci. 47, 95-103

Peiretti P.G., Meineri G., 2008. Effects on growth performance, carcass characteristics, and the fat and meat fatty acid profile of rabbits fed diets with chia (Salvia hispanica L.) seed supplements. Meat Sci. 80, 1116-1121
SAS, 1985. Users Guide: Basics. SAS Institute. Cary, NC

Tres A., Bou R., Codony R., Guardiola F., 2008. Influence of dietary doses of n-3- or n-6-rich vegetable fats and a-tocopheryl acetate supplementation on raw and cooked rabbit meat composition and oxidative stability. J. Agr. Food Chem. 56, 7243-7253

Wood J.D., Richardson R.I., Nute G.R., Fisher A.V., Campo M.M., Kasapidou E., Sheard P.R., Enser M., 2004. Effects of fatty acids on meat quality: a review. Meat Sci. 66, 21-32

Yahagi N., Shimano H., Hasty A.H. et al., 1999. A crucial role of sterol regulatory element-binding protein-1 in the regulation of lipogenic gene expression by polyunsaturated fatty acids. J. Biol. Chem. 274, 35840-35844 